\title{
Article \\ A Comparative Study of Aromatization Catalysts: The Advantage of Hybrid Oxy/Carbides and Platinum-Catalysts Based on Carbon Gels
}

\author{
Luisa M. Pastrana-Martínez *(D), Sergio Morales-Torres (D) and Francisco J. Maldonado-Hódar (D) \\ Department of Inorganic Chemistry, Faculty of Sciences, University of Granada, Avenida Fuente Nueva s/n, \\ ES-18071 Granada, Spain; semoto@ugr.es (S.M.-T.); fjmaldon@ugr.es (F.J.M.-H.) \\ * Correspondence: lpastrana@ugr.es; Tel.: +34-(958)-240-443
}

check for updates

Citation: Pastrana-Martínez, L.M.;

Morales-Torres, S.;

Maldonado-Hódar, F.J. A

Comparative Study of Aromatization Catalysts: The Advantage of Hybrid Oxy/Carbides and

Platinum-Catalysts Based on Carbon Gels. C 2021, 7, 21. https://doi.org/ $10.3390 / \mathrm{c} 7010021$

Received: 22 January 2021

Accepted: 9 February 2021

Published: 12 February 2021

Publisher's Note: MDPI stays neutral with regard to jurisdictional claims in published maps and institutional affiliations.

Copyright: (c) 2021 by the authors. Licensee MDPI, Basel, Switzerland. This article is an open access article distributed under the terms and conditions of the Creative Commons Attribution (CC BY) license (https:/ / creativecommons.org/licenses/by/ $4.0 /)$.

\begin{abstract}
This manuscript is focused on the relationship between sol-gel synthesis processes and the development of new active phases with fitted morphology, porosity and surface chemistry. The influence of the above parameters on the catalytic performance of the prepared materials for the aromatization of $\mathrm{n}$-hexane to benzene is also evaluated. Different series of catalysts were prepared, either using noble metals (i.e., $\mathrm{Pt}$ ) or metal oxides (i.e., Mo, W), as active phases. In both cases, the catalytic performance and stability of classical aromatization catalysts was significantly improved. Interesting one-pot carboreduction process of the metal oxide during carbonization is suggested as a real alternative for the preparation of high-performance aromatization catalysts, leading to the formation of less acidic and non-stoichiometric oxides and carbides.
\end{abstract}

Keywords: n-hexane; benzene; carbon nanomaterials; metal active-phases; aromatization

\section{Introduction}

Aromatic hydrocarbons are in high demand because they are the main feedstock for the production of a wide range of products including pharmaceuticals, cosmetics, dyes or polymers. The aromatization of cheap and abundant light alkanes into aromatic ones has been an important and alternative reaction to oil thermal cracking for the last 50 years, allowing the preparation of high-octane gasoline blending components from naphtha, among others [1-4].

The development of new catalysts for the valorization of light alkanes by transformation into aromatic products is an important challenge from an economic and scientific point of view. Traditional catalysts such as $\mathrm{Pt} / \mathrm{Cl}-\mathrm{Al}_{2} \mathrm{O}_{3}$ have provided low performances for light alkane $(C \leq 7)$ aromatization and, moreover, they can be deactivated by loss of chlorine which is formed by decomposition along a reaction of the $\mathrm{Cl}^{-}$groups present in the solid catalysts. In fact, chlorine is added to the feed causing corrosion and safety hazards [5]. Zeolites have been used as alternative non-chlorinated catalysts. The best performance for $\mathrm{C}_{6}$ reforming to benzene was described using Pt supported on zeolite $\mathrm{L}$ exchanged with $\mathrm{K}(\mathrm{Pt} / \mathrm{KL})$. These catalysts showed different characteristics including weak acidity, low coke formation, shape selectivity and resistance to sintering [6,7]. In previous works, we have also identified similar factors for Pt-supported catalysts on exchanged $\beta$-zeolites [8-10]. The exchange of zeolite with alkali or alkali-earth metals, namely Cs, induces textural changes, reducing the paraffin-adsorption capacity and the surface acidity, minimizing the coke formation and favoring the formation of small Pt clusters with specific Pt-support interactions, thus enhancing the aromatization yield.

Nowadays, the optimization of aromatization catalysts continues to be of great interest to the scientific community, as demonstrated by the high number of recent publications in this field [5,11-14]. Reforming of light alkanes is carried out using zeolites, mainly medium pore-size ZSM-5 zeolite which presents molecular shape selectivity towards benzene, 
toluene and xylene (BTX). Different promoters (mainly Ga, Zn and B) are used to enhance the aromatic yield by modifying the acidity of zeolite, favoring the alkane dehydrogenation and minimizing coke deposition.

In general, carbon materials present a basic character and a developed surface area and porosity, avoiding coke deposition and favoring the dispersion of supported metallic phases [15-19]. These properties could increase the performance of carbon-based catalysts in aromatization reactions. It was reported that high BTX yields can be obtained using Zn/HZSM5 catalysts for methanol aromatization, although deactivation by coking is strong. However, after regeneration, the residual of coke remaining on the zeolite surface can play an active role in the control of acidity, decreasing the acid sites' strength and distribution, in such a way that regenerated catalysts show good BTX yields and improved stability [20].

The number of references using carbon materials to develop aromatization catalysts is quite limited. Rodríguez-Ramos [21] suggested that the aromatization of n-heptane on $\mathrm{Pd} /$ activated carbon catalysts is a structure-insensitive reaction. As the Pt particle size decreases, hydrogenolysis is favored, but some isomerization and aromatization remain unchanged even after doping with $\mathrm{MgO}$ to increase the number of basic sites. When $\mathrm{Ru} /$ graphite is used as catalyst, [22] the electronic density of Ru-nanoparticles is enhanced by electron transfer from graphite. This results in an increase of the activity for the nhexane conversion, but accompanied only by a hydrogenolysis increase (aromatization levels only reached values around 10\%). On the other hand, Trunschke et al. [23] pointed out that the interactions of the carbon phase with metal oxides during thermal treatments remove the acidity of the oxides, avoiding undesirable and parallel reactions (cracking). The carbon phase also favors dehydrogenation of alkanes to alkenes, which in turn leads to an increased yield of $\mathrm{C}_{8}$ aromatization into ethylbenzene (EB) and o-xylene (OX) [23]. Similar conclusions were obtained by Hoang et al. [24]. They prepared $\mathrm{ZrO}_{2} / \mathrm{C}$ composites (77.2\% wt. $\mathrm{ZrO}_{2}$ ) pretreated at different temperatures (between 700 and $1600{ }^{\circ} \mathrm{C}$ ) for both $\mathrm{C}_{6}$ and $\mathrm{C}_{8}$ aromatization. In this case, the carbon phase avoids the $\mathrm{ZrO}_{2}$ sintering and induces the destruction of acid sites during thermal pretreatments. The most selective catalyst is obtained after pretreatment at $1000{ }^{\circ} \mathrm{C}$, providing a benzene selectivity of $67 \%$.

Together with classical activated carbons, today there is available a large amount of advanced carbon materials (from 1D to 3D nanomaterials) with improved and fitted properties to be used in catalysis $[15,17,18,25]$. Among them, carbon gels (aerogels or xerogels) present additional advantages such as homogeneity and purity; moreover, its chemical and porous characteristics can be specifically designed and controlled during the sol-gel process, thus showing large possibilities in developing new catalysts [26]. Different aromatization catalysts containing several active phases such as metal oxides of $\mathrm{Cr}$, Mo or W, or noble metals like Pt have been prepared by modifying their synthesis procedure [27-29]. In this manuscript, the advantage of using carbon materials in the design of new aromatization catalysts is briefly summarized. The results obtained in the n-hexane aromatization show that these easily prepared catalysts are a feasible alternative to metalexchanged zeolitic materials, improving aspects such as stability or selectivity. Correlations between the variables of preparation (e.g., surfactants, drying, carbonization temperature), the morphology and active phases formed (non-stoichiometric oxides/carbides) and the catalytic performances are analyzed.

\section{Results and Discussion}

Today, one of the most deeply studied systems for the aromatization of n-hexane is the metal-exchanged ZSM5 zeolite. Tshabalala et al. [30] pointed out the higher activity and stability of acid HZSM5 regarding Ga, Mo or Zn-exchanged ZSM5, where mainly $\mathrm{Ga} / \mathrm{ZSM} 5$ deactivated quickly. The highest aromatization selectivity was observed for Zn/ZSM5 (around 43\%) while Mo/ZSM5 exhibits the lowest selectivity values (between 20 and $25 \%$ ), even worse than those observed for acid forms. More recently, Huyen [31] et al. prepared Zn/ZSM-5 and B-Zn/ZSM5 catalysts. Zn/ZSM5 is more active and selective to 
benzene, but deactivated faster. The selectivity reached $52 \%$ at $500{ }^{\circ} \mathrm{C}$, but also decreased with deactivation after $3 \mathrm{~h}$ on stream.

We have prepared different catalyst series. Figure 1 summarizes the performance of Mo and W-carbon xerogels (prepared following the methodology b in the Section 3) after direct carbonization at $500{ }^{\circ} \mathrm{C}$. The higher activity of Mo catalysts compared to the W-ones is noteworthy, and it is also slightly more selective to benzene. Conversion increased more or less linearly in both cases with increasing temperature, but in this sense undesired cracking increased at the expense of aromatization.

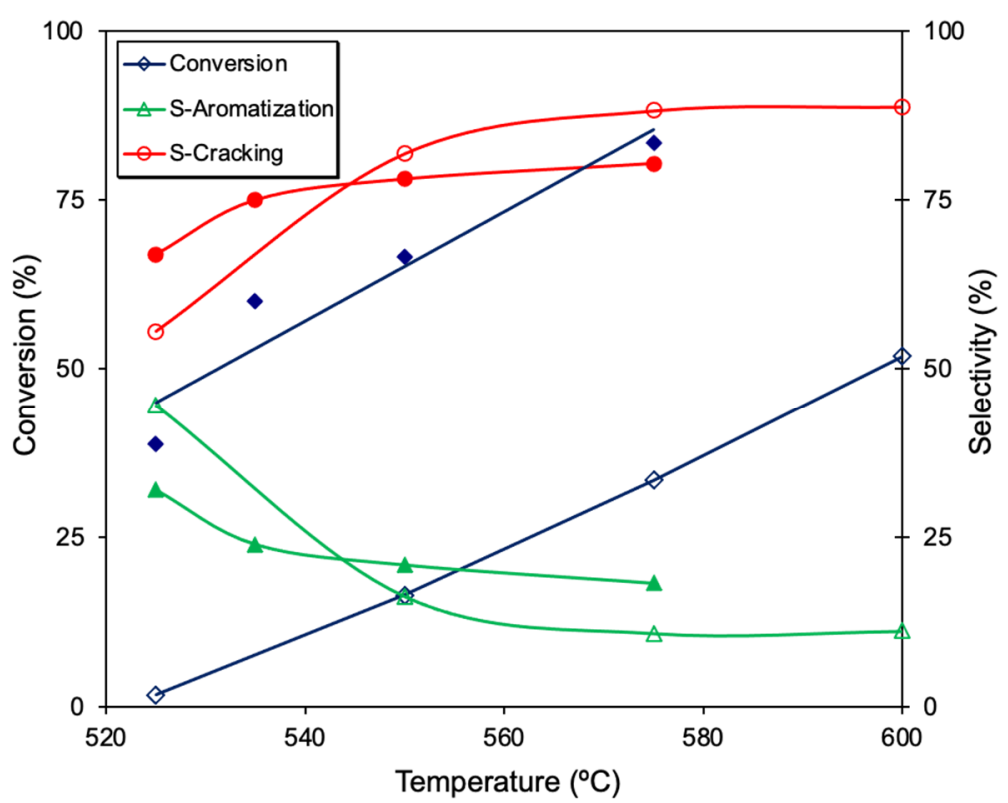

Figure 1. Conversion and products distribution obtained with $\mathrm{W}$ (opened symbols) and Mo (closed symbols) prepared as doped carbon xerogels at $500{ }^{\circ} \mathrm{C}$ (adapted from ref. [27]).

The physicochemical properties of these samples are summarized in Table 1. Both carbon aerogels showed a similar pore size distribution, being samples with high macropore volumes and $\mathrm{S}_{\mathrm{BET}}$ around $500 \mathrm{~m}^{2} \mathrm{~g}^{-1}$, but without any appreciable mesoporosity. The difference between the samples is related to the chemical composition of their surfaces. In spite of the fact that both samples were prepared with a similar metal content in the starting solution, the total metal content detected by TG is higher in the case of the Mo sample (i.e., $1.9 \%$ and $1.4 \%$ wt. for Mo500 and W500, respectively). This implies a different M-C interaction, influencing processes such as lixiviation during the solvent exchange process. It is also noteworthy that the reduction of the Mo species during the carbonization even at $500{ }^{\circ} \mathrm{C}$ is favored, regarding the $\mathrm{W}$-ones. Carbon evolved as $\mathrm{CO}_{\mathrm{x}}$ and $\mathrm{Mo}(\mathrm{VI})$ reduced in a significant proportion to $\mathrm{Mo}(\mathrm{V})$. This deeper gasification during the carbonization process also increased the total metal content in this sample regarding the W500, where tungsten remains as W(VI). Moreover, the surface metal content detected by XPS of Mo-500 is also higher than for W500, indicating a best dispersion (smaller sintering) of the Mo phase.

Table 1. Physicochemical properties of metal-doped carbon catalysts.

\begin{tabular}{|c|c|c|c|c|c|c|}
\hline Sample & $\begin{array}{l}\text { Metal } \\
\text { (\%wt.) }\end{array}$ & $\begin{array}{l}\text { XPS } \\
\text { M/C }\end{array}$ & $\begin{array}{l}\text { Active } \\
\text { Species }\end{array}$ & $\begin{array}{c}S_{\mathrm{BET}} \\
\left(\mathrm{m}^{2} \mathrm{~g}^{-1}\right)\end{array}$ & $\begin{array}{c}V_{\text {macro }} \\
\left(\mathrm{cm}^{3} \mathrm{~g}^{-1}\right)\end{array}$ & $\begin{array}{c}V_{\text {meso }} \\
\left(\mathrm{cm}^{3} \mathrm{~g}^{-1}\right)\end{array}$ \\
\hline Mo500 & 1.9 & 7.6 & $\begin{array}{l}\text { Mo (V) } 82 \% \\
\text { Mo (VI) } 18 \%\end{array}$ & 481 & 1.40 & 0.00 \\
\hline W500 & 1.4 & 1.4 & W (VI) $100 \%$ & 528 & 1.32 & 0.05 \\
\hline
\end{tabular}

$\mathrm{S}_{\mathrm{BET}}=$ apparent surface area; $\mathrm{V}_{\text {macro }}=$ macropore volume; $\mathrm{V}_{\text {meso }}=$ mesopore volume. 
Different nature and distributions of active sites are obtained depending on the experimental conditions used for the preparation of metal-carbon doped gels. By increasing the carbonization temperature up to $1000{ }^{\circ} \mathrm{C}$, it forced the progressive reduction of the metal oxides. In this sense, a mixture of Mo (III) and Mo (V) in a ratio of $45 / 55$ was observed for the sample Mo-1000 (results not shown) [27], however, although $\mathrm{W}$ remains mainly $(93 \%)$ as W (VI), there is observed a certain carbidization ( $7 \%$ of WC). Comparing the results obtained with $\mathrm{W}$-doped carbon aerogels carbonized at $500{ }^{\circ} \mathrm{C}$ and $1000{ }^{\circ} \mathrm{C}$ [27], it was pointed out that the total acidity determined by isopropanol decomposition is maintained, but strongly decreased the proportion of the propene/acetone formed in this reaction, which denotes a strong increase of basic centers regarding those acid ones with increasing carbonization temperature. This has led to a strong increase in the selectivity to benzene using W1000 regarding W500, which is enhanced from 17 to $38 \%$ at $550{ }^{\circ} \mathrm{C}$. These results are in agreement with those previously published $[23,24]$, in which the carbon phase determines the dispersion and acid character of metal oxides.

In spite of the large reduction of Mo phases, the carbidization of these non-stoichiometric oxides during carbonization is not observed. It was previously suggested that Mocarbidization requires the presence of $\mathrm{H}_{2}$ and temperatures ranging $700{ }^{\circ} \mathrm{C}$ [32]. Nevertheless, because aromatization is carried out in the presence of $\mathrm{H}_{2}$, the formation of carbides along the reaction cannot be ruled out. In fact, Delporte et al. [33] observed the formation of carbide and oxycarbide species $\left(\mathrm{MoC}_{x} \mathrm{O}_{y}\right)$ using $\mathrm{MoO}_{3}$ catalyst for the isomerization of $\mathrm{n}$-hexane at $350{ }^{\circ} \mathrm{C}$. They reported that the Mo phases formed are highly dependent of the $\mathrm{H}_{2}$ / hexane ratio, determining the catalyst's performance.

In our case, when the evolution of conversion and selectivity with the time on stream were analyzed, a very stable performance (Figure 2) of Mo-doped samples was observed, probably also indicating a negligible transformation of the catalyst's surface. It is noteworthy that this stability is observed in spite of the same sample being used at different temperatures (Figure 1) for around $3 \mathrm{~h} . \mathrm{MoO}_{\mathrm{x}}$ are normally used as isomerization catalysts to obtain branched alkanes, however, it is observed that in our case the isomerization is negligible independent of the reaction temperature or time on stream. Cracking is the main process, favored by the acidity of the catalysts and the increasing reaction temperature.

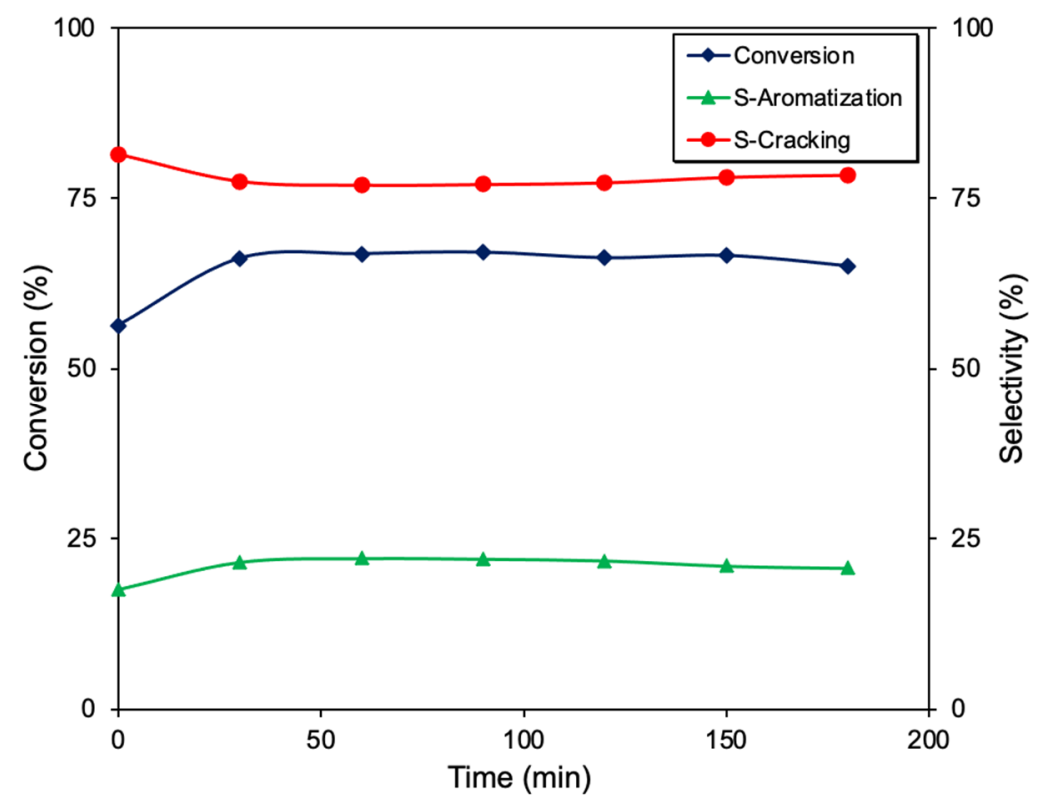

Figure 2. Conversion and products distribution obtained with Mo500 carbon aerogel at $550{ }^{\circ} \mathrm{C}$, as a function of time on stream.

Molybdenum carbide catalysts have attracted the attention of different research groups $[34,35]$ as aromatization catalysts of light alkanes, being proposed as alternatives 
to noble metal $(\mathrm{Pt})$ catalysts. The sol-gel procedure to obtain Mo-doped carbon gels was modified and samples were prepared following the methodology (c), in the Section 3. This implies that the first RF polymerization step is carried out in agitated batch reactors with the presence/absence of surfactants, thus defining the morphology of materials (fibers, spheres, etc. can be formed). Gels are partially cured in suspension before doping with the corresponding active phase. This procedure is faster than procedure $(b)$, avoiding large cure periods inside the glass molds, but also avoids the formation of metal nanoparticles trapped inside the organic structure of the RF organic gels. After pre-gelation, nanoparticles are forced to be formed on the surface of previously gelled RF-structures. Additionally, surfactant molecules are incorporated into the RF chemical structure forming RFS composites that offer improved anchoring sites for metal adsorption during the impregnation process [29], allowing the obtaining of a high coverage on the carbon surface of metal nanoparticles (Figure 3 ) even after thermal carbonization at high temperature $\left(900{ }^{\circ} \mathrm{C}\right)$.

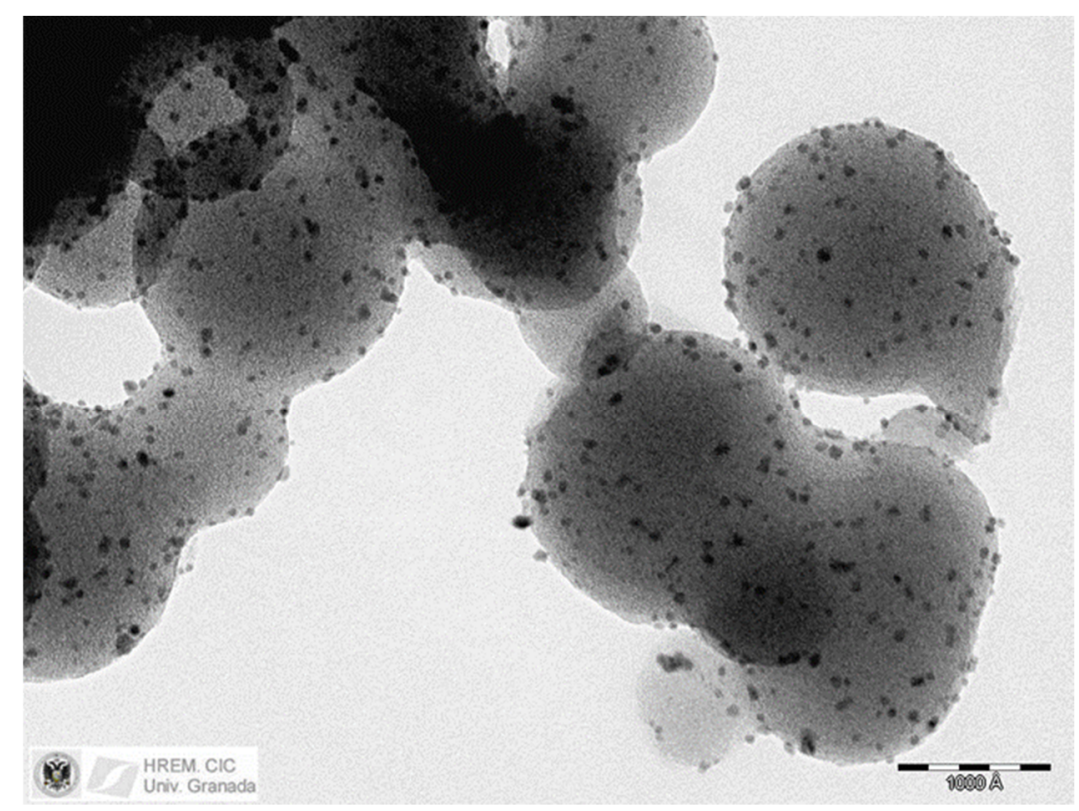

Figure 3. Highly dispersed Mo nanoparticles on carbon xerogel S10 (RF + CTAB cationic surfactant + t-butanol) after carbonization at $900{ }^{\circ} \mathrm{C}$.

The interaction of the RFS composites with the metal precursor is mainly determined by the nature of the surfactant. The stronger the RFS-Mo links, the deeper the reduction of the Mo phase will be observed during carbonization [28]. The XPS analysis of samples prepared by this procedure indicates that up to $60 \%$ of the Mo detected in surface is forming like $\beta-\mathrm{Mo}_{2} \mathrm{C}$; this phase is also detected by XRD in some cases [36]. Thus, highly dispersed Mo nanoparticles can be easily formed and carburized when supported on nanostructured RFS gels following an easy "one pot" procedure, mainly when using a cationic surfactant that interacts attractively with the anionic RF macromolecule.

Figure 4 shows the catalytic performance of S7 catalysts, as an example, showing the typical evolution of this catalytic series. This sample is synthesized in the presence of cationic $\mathrm{CTAB}, \mathrm{TMB}$ and t-butanol as co-surfactants, and after carbonization the ratio $\mathrm{MoO}_{\mathrm{x}} / \mathrm{MoC}_{\mathrm{x}}=42 / 58$. As in the previous Mo series, conversion increased more or less linearly with temperature, isomerization is negligible and cracking is favored with increasing temperature. Due to the strong degree of reduction of the Mo-oxide phase, the smaller activity of S7 regarding Mo-500 is noteworthy, which showed a total n-hexane conversion at $580{ }^{\circ} \mathrm{C}$. However, selectivity to benzene reached higher values (over $60 \%$ at $500{ }^{\circ} \mathrm{C}$ ). In these experimental conditions $\left(500^{\circ} \mathrm{C}\right.$; Figure $\left.4 \mathrm{~b}\right)$, both conversion and selectivity slowly decreased with time on stream. Thus, less active but more selective phases are obtained by the progressive reduction of the Mo phase and the formation of Mo oxycarbides. Even when 
increasing temperature, the selectivity at $550{ }^{\circ} \mathrm{C}$ shows values at around $50 \%$, increasing significantly from values ranging $25 \%$ for Mo-500 catalyst (Figure 1 ) at this temperature.
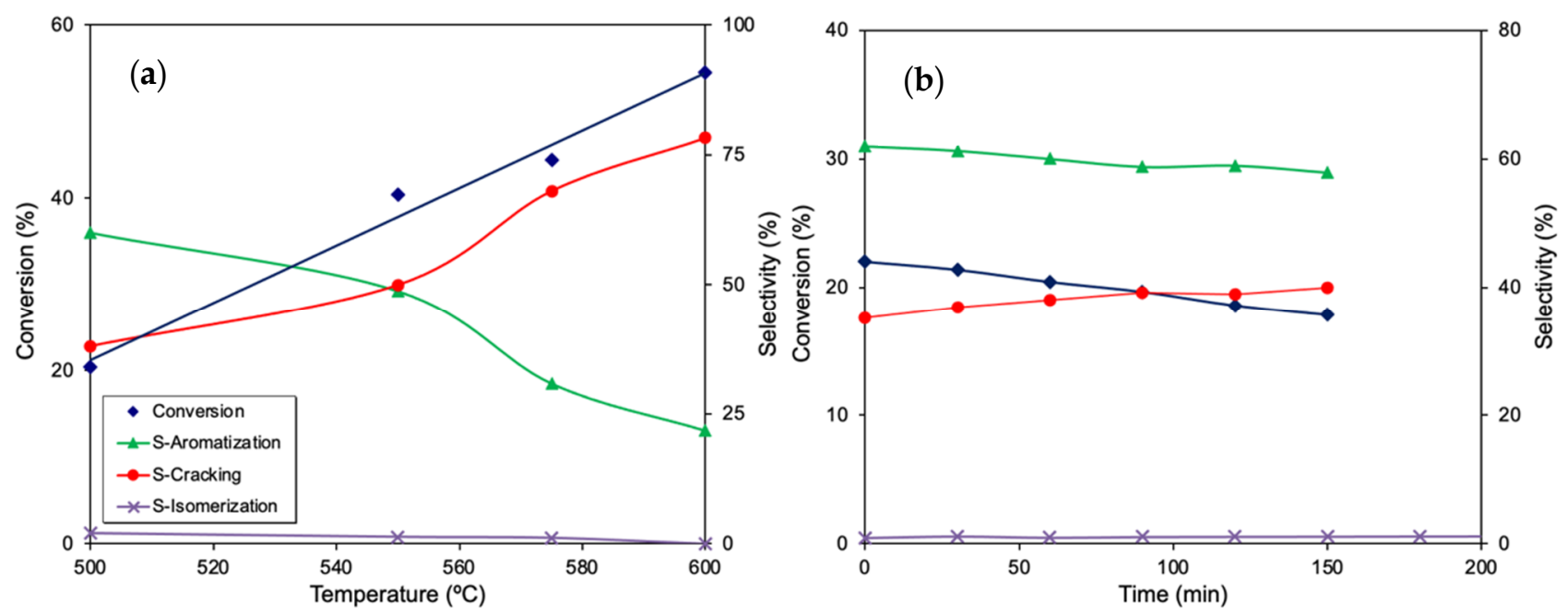

Figure 4. Evolution of conversion and products distribution for sample S7: (a) as a function of temperature and (b) as a function of time on stream at $500{ }^{\circ} \mathrm{C}$.

Pt catalysts [28] were prepared by classical incipient wetness impregnation using as support a mesoporous carbon aerogel previously synthesized (procedure a). After pretreatments in He flow at different temperatures, only metallic $\mathrm{Pt}^{0}$ species were detected. The catalytic performance is related therefore only with the dispersion of metallic nanoparticles. Figure 5 summarizes the performance of C900 2Pt catalyst, which contains a $2 \% \mathrm{of} \mathrm{Pt}$ (\%wt.). The mean Pt particle size increased from 2.8 to $7.3 \mathrm{~nm}$ after pretreatment at 600 or $900{ }^{\circ} \mathrm{C}$ in He flow, respectively. At a glance, significant differences are observed regarding the previous series using oxide/oxycarbide catalysts such as: (i) Pt catalysts are active at significantly lower temperatures; (ii) in general, benzene is the main reaction product obtained; (iii) significant isomerization process takes place at low temperature; and (iv) at higher temperatures, conversion increases favoring aromatization regarding isomerization and cracking.
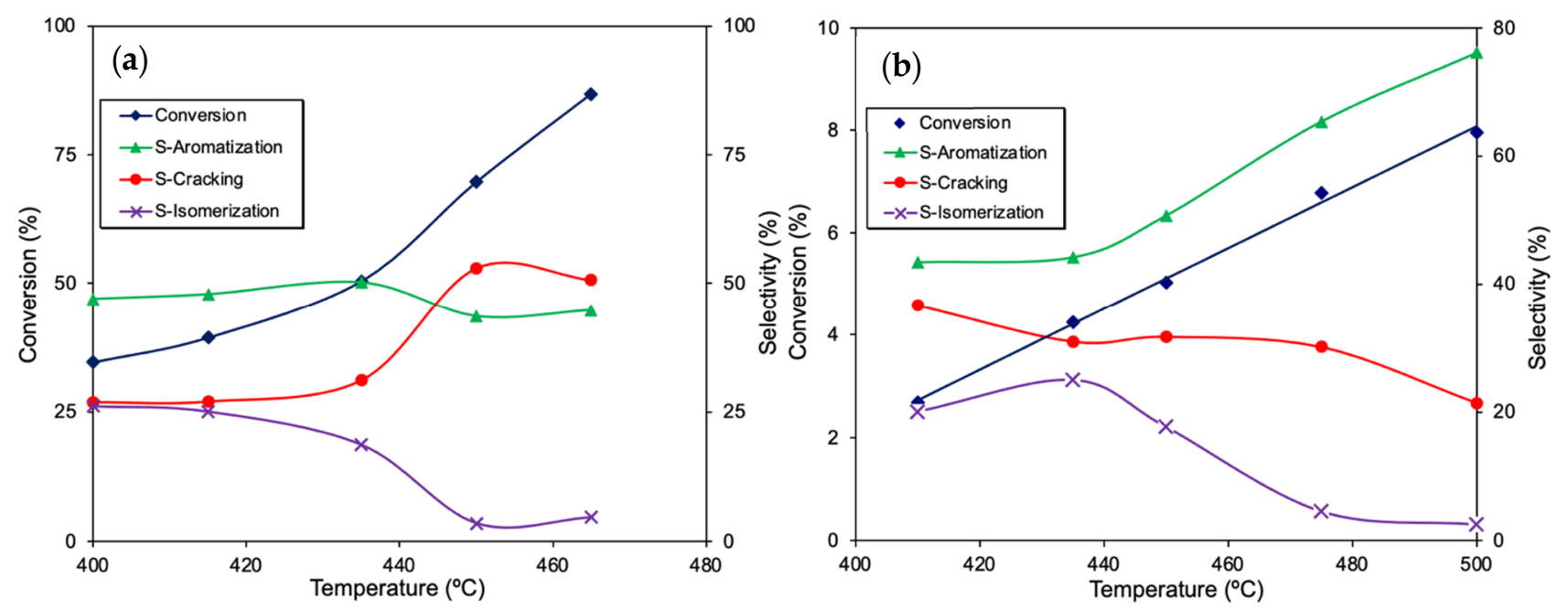

Figure 5. Evolution of conversion and products distribution for sample C900 2Pt as a function of temperature after pretreatment in $\mathrm{He}$ at (a) $600{ }^{\circ} \mathrm{C}$ and (b) $900{ }^{\circ} \mathrm{C}$. 
Small Pt nanoparticles obtained at low pretreatment temperature are highly active and n-hexane conversion increased from 35 to $90 \%$ in a short temperature range (between 400 and $465^{\circ} \mathrm{C}$ ); in this case, aromatization remains more or less constant and cracking increased at the expense of isomerization processes. With increases in the Pt particle size there is a strong reduction of the catalyst activity, but aromatization is strongly favored with increasing reaction temperature (reaching values of $78 \%$ at $500{ }^{\circ} \mathrm{C}$ ), therefore decreasing in this sense both isomerization and cracking. These changes clearly point out the structuresensitive character of aromatization on Pt-supported catalysts.

A similar effect was observed when increasing the Pt content from 2 to $5 \%$ (Table 2). Conversion decreased in spite of the higher Pt content, but benzene becomes the main product obtained, with a selectivity value of around $65 \%$. Moreover, it is also noteworthy the high stability of Pt catalysts when supported on carbon aerogels (Figure 6). These results point out the importance of the carbon gel materials used to develop highly selective and stable catalysts for the aromatization of light alkanes (n-hexane). In general, the main aromatization product detected was benzene, while toluene was not detected. Cracking leads to the formation of the $\mathrm{C} 1-\mathrm{C} 5$ compounds and methylcyclopentane (MCP) was found as the main isomerization product. Conversion was calculated taking into account the amount of hexane transformed and selectivity as the amount of each detected product over the total hexane consumed. Thus, the values of cracking selectivity presented include the amounts of the C1-C5 compounds [27,28].

Table 2. Influence of the Pt content on the catalytic performance of supported catalysts pretreated at $600{ }^{\circ} \mathrm{C}$. Conversion and products distribution obtained at $475^{\circ} \mathrm{C}$.

\begin{tabular}{lcccccc}
\hline Sample & $\begin{array}{c}\mathbf{d ~ P t} \\
(\mathbf{n m})\end{array}$ & $\begin{array}{c}\mathbf{C} \\
\mathbf{( \% )}\end{array}$ & $\begin{array}{c}\text { S Crack } \\
\mathbf{( \% )}\end{array}$ & $\begin{array}{c}\text { S Iso } \\
\mathbf{( \% )}\end{array}$ & $\begin{array}{c}\text { S Arom } \\
\mathbf{( \% )}\end{array}$ & $\begin{array}{c}\text { Yield Arom } \\
\mathbf{( \% )}\end{array}$ \\
\hline C900 2Pt & 2.8 & 86.8 & 50.7 & 4.7 & 44.7 & 38.8 \\
C900 5Pt & 9.9 & 60.5 & 32.7 & 2.4 & 64.9 & 39.3 \\
\hline
\end{tabular}

$\mathrm{d} \mathrm{Pt}=\mathrm{Pt}$ particle size; $\mathrm{C}=$ Conversion; $\mathrm{S}$ Crack = Selectivity to cracking; S Iso = Selectivity to isomerization; $\mathrm{S}$ Arom $=$ Selectivity to aromatization .

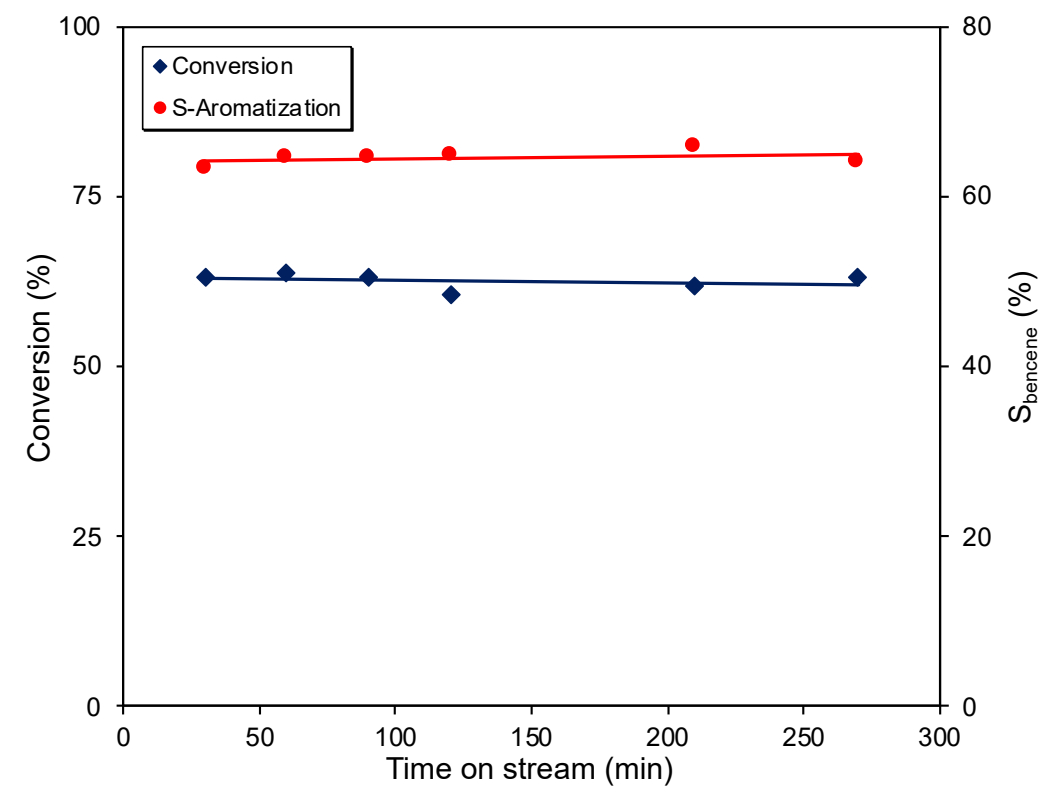

Figure 6. Evolution of conversion and benzene selectivity as a function of time on stream at $475^{\circ} \mathrm{C}$, using C900 5Pt catalysts pretreated at $600{ }^{\circ} \mathrm{C}$.

\section{Materials and Methods}

Carbon gel supports and the posterior functionalization with different active phases were synthesized following the method described by Pekala [37] with different modifications: 
(a) Preparation of carbon-gel supports (Figure 7): Resorcinol (R) and formaldehyde (F) in a molar ratio of $\mathrm{R} / \mathrm{F}=1 / 2$ and $\mathrm{Na}_{2} \mathrm{CO}_{3}$, as polymerization catalyst $(\mathrm{C})$ are dissolved in the appropriate amounts of distilled water (W). Solutions are cast into glass molds, sealed and cured for 1 day at room temperature, 2 days at $50{ }^{\circ} \mathrm{C}$ and 5 days at $80^{\circ} \mathrm{C}$. After that, gel rods are cut in pellets and introduced in acetone to remove the water inside the pores. Finally, gels were supercritically dried with carbon dioxide to obtain the corresponding organic RF aerogels or dried in the oven at $120^{\circ} \mathrm{C}$ obtaining the corresponding xerogels. Pyrolysis of organic gels to obtain the derivative carbon gels is carried out in a tubular furnace under $\mathrm{N}_{2}$ flow by heating up to different temperatures $\left(500\right.$ or $1000{ }^{\circ} \mathrm{C}$ ) with a heating rate between 0.5 and $1.5^{\circ} \mathrm{C} \mathrm{min}{ }^{-1}$.

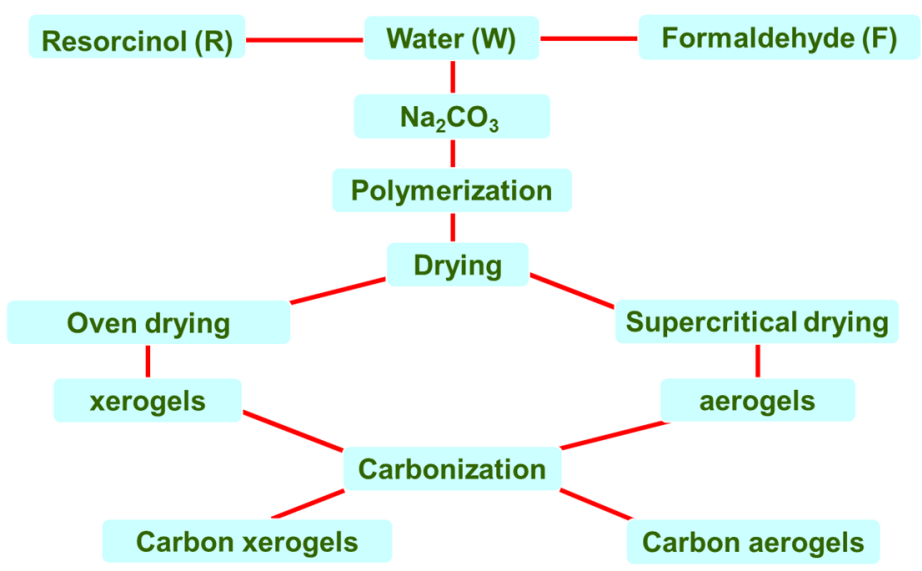

Figure 7. Sequence followed for the preparation of carbon-gel supports.

After obtaining the corresponding carbon gels, supported catalysts were prepared by classical incipient wet impregnation with the corresponding metal salt precursors $([\mathrm{Pt}$ $\left(\mathrm{NH}_{3}\right)_{4} \mathrm{Cl}_{2}$ ) and thermally pretreated in situ in inert (He) at temperatures $600-900{ }^{\circ} \mathrm{C}$.

(a) Metal-doped carbon gels were obtained directly by replacing $\mathrm{Na}_{2} \mathrm{CO}_{3}$ by the corresponding metal precursor in the starting solution $[30,38]$. In this case, ammonium molybdate or tungstate was used. The rest of the synthesis procedure was maintained as in procedure (a). In such a way, simultaneous carbonization of the RF organic fraction and decomposition of the precursor salts occurs during the same thermal process, leading directly to materials suitable to be used in catalysis.

(b) Metal-supported carbon xerogels were obtained in powder following a procedure in two steps [29]; firstly, the polymerization of RF in the presence/absence of surfactants is carried out in a batch reactor at $50^{\circ} \mathrm{C}$ for $2 \mathrm{~h}$; after the morphology of the organic $\mathrm{RF}$ is defined, the solid in suspension is doped with metal precursors, then the temperature of the bath is increased up to $90{ }^{\circ} \mathrm{C}$ for an additional $24 \mathrm{~h}$, allowing the complete polymerization of the organic fraction. Finally, solids are recovered by filtration, properly washed, dried in an oven and finally carbonized at $900{ }^{\circ} \mathrm{C}$. The procedure is summarized in Figure 8. 


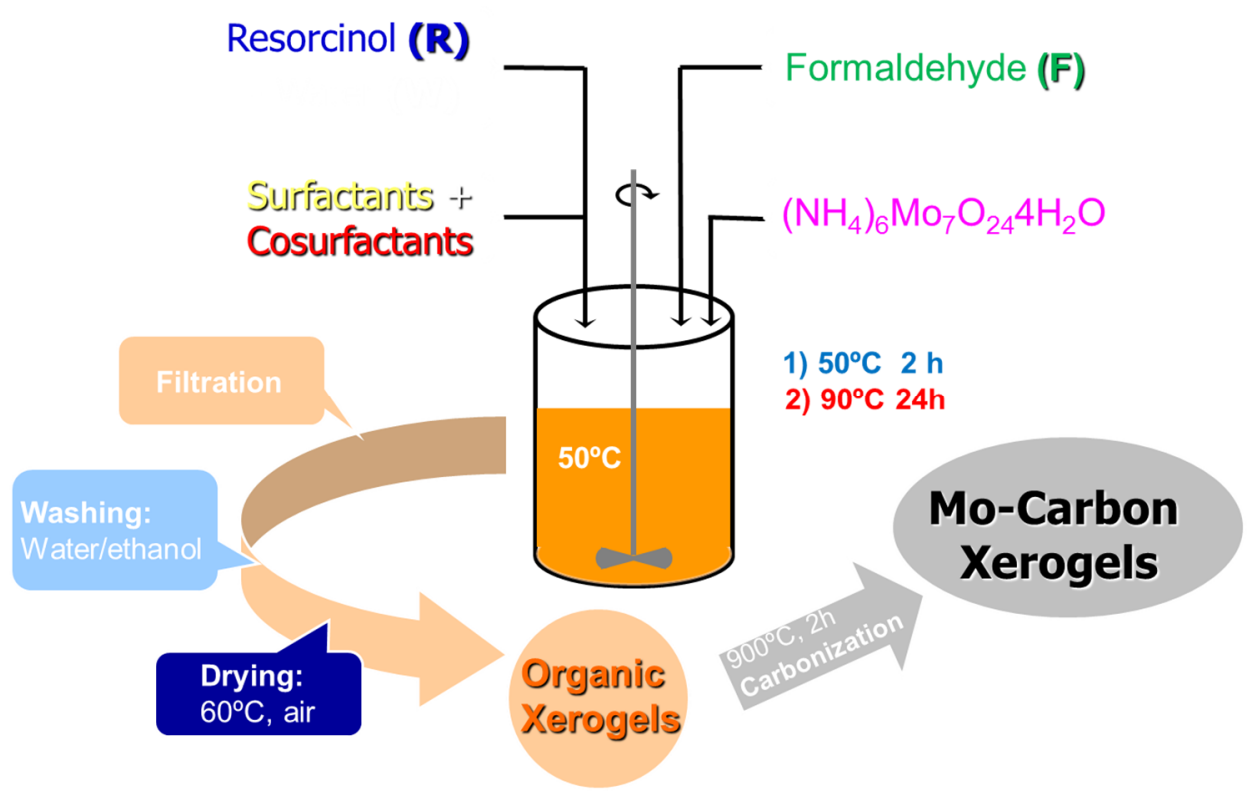

Figure 8. Preparation of metal-doped carbon xerogel powder.

Catalysts were properly texturally and chemically characterized using complementary techniques, including mercury porosimetry and gases adsorption $\left(\mathrm{N}_{2}\right.$ at $-196{ }^{\circ} \mathrm{C}$ and $\mathrm{CO}_{2}$ at $\left.0{ }^{\circ} \mathrm{C}\right), \mathrm{XRD}, \mathrm{SEM}, \mathrm{HRTEM}, \mathrm{XPS}, \mathrm{TG}$, etc.

The aromatization of $n$-hexane experiments was carried out at atmospheric pressure using a quartz micro-reactor with $0.15 \mathrm{~g}$ catalyst forming a fixed bed. The reactor was fed with a continuous flow, $60 \mathrm{~cm}^{3} \mathrm{~min}^{-1}$, of a mixture $50 \% \mathrm{He} / 50 \% \mathrm{H}_{2}$ bubbled in a hexane saturator cooled to fix the hexane concentration at $2.5 \% v / v$. Products were analyzed by gas chromatography, using a flame ionization detector and a Chromosorb column. Conversion was defined on the basis of the n-hexane disappearance and selectivity as the fraction of hexane molecules transformed into each detected product.

\section{Conclusions}

The main drawback of aromatization catalysts is related to the loss of activity, selectivity and stability, mainly due to a fast deactivation by coke. Because these reactions are carried out in the absence of oxygen, guaranteeing the carbon stability, the use of carbon gel-based catalysts results in evident advantages based on a developed porous texture and basic character.

The sol-gel technology applied to the development of an aromatization catalyst presents a different alternative to optimize the performance of active phases, defining the nanostructure, nature and distribution of the corresponding active phases. Using non-noble active phases $(\mathrm{Mo}, \mathrm{W})$, the progressive reduction of the metal oxide phases takes place simultaneously to the carbonization of the organic phase. These processes minimize the acidity of the catalysts, increasing the aromatization selectivity. When these samples are synthesized in the presence of cationic surfactant (CTAB), new anchoring sites for metals are produced favoring a strong dispersion of the active phase and a deeper degree of reduction/carbidization. The formation of $\mathrm{Mo}_{2} \mathrm{C}$ again increases the aromatization selectivity (up to $60 \%$ in some cases) regarding samples where the active phase remains as metal oxide. In this catalyst series, the strength and distribution of acid sites determines the product distribution, increasing acidity and reaction temperature, favoring cracking processes.

Using noble metals $(\mathrm{Pt})$ as active phase, the aromatization process takes place on the metallic surface $\left(\mathrm{Pt}^{0}\right)$ and the reaction strongly depends on the Pt particle size. The $\mathrm{C}_{6}$ aromatization is a structure-sensitive reaction. Small nanoparticles are more active, but conversion increases with temperature, favoring cracking. With increasing Pt particle size, conversion decreased but the selectivity to benzene strongly increased, reaching values 
around $70 \%$. In this case, conversion increased favoring aromatization processes, thus obtaining high conversion and aromatization selectivity values, both aspects being stable for a long time on streams.

Author Contributions: L.M.P.-M. and S.M.-T.; investigation, L.M.P.-M. and S.M.-T.; writing-original draft preparation, F.J.M.-H.; writing—review and editing, L.M.P.-M. and S.M.-T.; supervision, F.J.M.H.; funding acquisition, L.M.P.-M., S.M.-T. and F.J.M.-H. All authors have read and agreed to the published version of the manuscript.

Funding: This work was supported by the Spanish Project ref. RTI 2018-099224-B100 funded by ERDF/Ministry of Science, Innovation and Universities-State Research Agency and the Nano4Fresh project (ref. PCI2020-112045), as part of the PRIMA Programme supported by the European Union.

Acknowledgments: L.M.P.-M. (RYC-2016-19347) and S.M.-T. (RYC-2019-026634-I/AEI/10.13039/ 501100011033) acknowledge the Spanish Ministry of Economy and Competitiveness (MINECO), the State Research Agency and the European Social Found for their Ramón y Cajal research contracts. "Unidad de Excelencia Química Aplicada a Biomedicina y Medioambiente" of the University of Granada (UEQ-UGR) is gratefully acknowledged for the technical assistance.

Conflicts of Interest: The authors declare no conflict of interest.

\section{References}

1. Derouane, E.G.; Vanderveken, D.J. Structural recognition and preorganization in zeolite catalysis: Direct aromatization of n-hexane on zeolite L-based catalysts. Appl. Catal. 1988, 45, L15-L22. [CrossRef]

2. Guisnet, M.; Gnep, N.S.; Alario, F. Aromatization of short chain alkanes on zeolite catalysts. Appl. Catal. A Gen. 1992, 89, 1-30. [CrossRef]

3. Mahale, R.S.; Parikh, P.A. Aromatization of n-hexane: Synergism afforded by C1-C3 alcohols. Chem. Eng. Sci. 2020, $217,115519$. [CrossRef]

4. Nezam, I.; Zhou, W.; Gusmão, G.S.; Realff, M.J.; Wang, Y.; Medford, A.J.; Jones, C.W. Direct aromatization of CO2 via combined CO2 hydrogenation and zeolite-based acid catalysis. J. CO2 Util. 2021, 45, 101405. [CrossRef]

5. Zhang, P.; Liu, J.; Cui, J.; Yang, Y.; Hu, C.-L.; Liu, B.-J. Preparation of Pt/CeL reforming catalyst and its performance in the aromatization of naphtha. J. Fuel Chem. Technol. 2019, 47, 318-322. [CrossRef]

6. Besoukhanova, C.; Barthomeuf, D.; Breysse, M.; Bernard, J.R. Unusual Properties of Platinum Alkaline Zeolites in N-Hexane Dehydrocyclisation and Benzene Hydrogenation. In Studies in Surface Science and Catalysis; Seiyama, T., Tanabe, K., Eds.; Elsevier: Amsterdam, The Netherlands, 1981; Volume 7, pp. 1410-1411.

7. Tauster, S.J.; Steger, J.J. Molecular die catalysis: Hexane aromatization over Pt/KL. J. Catal. 1990, 125, 387-389. [CrossRef]

8. Maldonado-Hódar, F.J.; Silva, J.M.; Ribeiro, F.R.; Ribeiro, M.F. Influence of the exchanged cation in coke deposition during n-hexane reactions on Pt/M zeolite catalysts. Catal. Lett. 1997, 48, 69-73. [CrossRef]

9. Bécue, T.; Maldonado-Hodar, F.J.; Antunes, A.P.; Silva, J.M.; Ribeiro, M.F.; Massiani, P.; Kermarec, M. Influence of Cesium in $\mathrm{Pt} / \mathrm{NaCs} \beta$ on the Physico-Chemical and Catalytic Properties of the Pt Clusters in the Aromatization of n-Hexane. J. Catal. 1999, 181, 244-255. [CrossRef]

10. Maldonado, F.J.; Bécue, T.; Silva, J.M.; Ribeiro, M.F.; Massiani, P.; Kermarec, M. Influence of the Alkali in Pt/Alkali- $\beta$ Zeolite on the Pt Characteristics and Catalytic Activity in the Transformation of n-Hexane. J. Catal. 2000, 195, 342-351. [CrossRef]

11. Wongnongwa, Y.; Kidkhunthod, P.; Sukkha, U.; Pengpanich, S.; Thavornprasert, K.-A.; Phupanit, J.; Kungwan, N.; Feng, G.; Keawin, T.; Jungsuttiwong, S. Local structure elucidation and reaction mechanism of light naphtha aromatization over Ga embedded H-ZSM-5 zeolite: Combined DFT and experimental study. Microporous Mesoporous Mater. 2020, 306, 110414. [CrossRef]

12. Uslamin, E.A.; Saito, H.; Sekine, Y.; Hensen, E.J.M.; Kosinov, N. Different mechanisms of ethane aromatization over Mo/ZSM-5 and Ga/ZSM-5 catalysts. Catal. Today 2020. [CrossRef]

13. Fadaeerayeni, S.; Shan, J.; Sarnello, E.; Xu, H.; Wang, H.; Cheng, J.; Li, T.; Toghiani, H.; Xiang, Y. Nickel/gallium modified HZSM-5 for ethane aromatization: Influence of metal function on reactivity and stability. Appl. Catal. A Gen. 2020, 601, 117629. [CrossRef]

14. Liu, G.; Liu, J.; He, N.; Sheng, S.; Wang, G.; Guo, H. Pt supported on Zn modified silicalite-1 zeolite as a catalyst for n-hexane aromatization. J. Energy Chem. 2019, 34, 96-103. [CrossRef]

15. Su, D.S.; Perathoner, S.; Centi, G. Catalysis on nano-carbon materials: Going where to? Catal. Today 2012, 186, 1-6. [CrossRef]

16. Vivo-Vilches, J.F.; Bailón-García, E.; Pérez-Cadenas, A.F.; Carrasco-Marín, F.; Maldonado-Hódar, F.J. Tailoring the surface chemistry and porosity of activated carbons: Evidence of reorganization and mobility of oxygenated surface groups. Carbon 2014, 68, 520-530. [CrossRef]

17. Figueiredo, J.L. Nanostructured porous carbons for electrochemical energy conversion and storage. Surf. Coat. Technol. 2018, 350, 307-312. [CrossRef] 
18. Morales-Torres, S.; Maldonado-Hódar, F.J.; Pérez-Cadenas, A.F.; Carrasco-Marín, F. Design of low-temperature Pt-carbon combustion catalysts for VOC's treatments. J. Hazard. Mater. 2010, 183, 814-822. [CrossRef] [PubMed]

19. Calvino-Casilda, V.; López-Peinado, A.J.; Durán-Valle, C.J.; Martín-Aranda, R.M. Last Decade of Research on Activated Carbons as Catalytic Support in Chemical Processes. Catal. Rev. 2010, 52, 325-380. [CrossRef]

20. Zhang, G.; Zhang, X.; Bai, T.; Chen, T.; Fan, W. Coking kinetics and influence of reaction-regeneration on acidity, activity and deactivation of Zn/HZSM-5 catalyst during methanol aromatization. J. Energy Chem. 2015, 24, 108-118. [CrossRef]

21. Rodríguez-Ramos, I.; Guerrero-Ruiz, A. Transformations of n-heptane over Pt/activated carbon catalysts. Appl. Catal. A Gen. 1994, 119, 271-278. [CrossRef]

22. Guerrero-Ruiz, A.; Bachiller-Baeza, B.; Rodríguez-Ramos, I. Catalytic properties of carbon-supported ruthenium catalysts for n-hexane conversion. Appl. Catal. A Gen. 1998, 173, 231-238. [CrossRef]

23. Trunschke, A.; Hoang, D.L.; Radnik, J.; Brzezinka, K.W.; Brückner, A.; Lieske, H. Transition metal oxide/carbon composite catalysts for n-alkane aromatization: Structure and catalytic properties. Appl. Catal. A Gen. 2001, 208, 381-392. [CrossRef]

24. Hoang, D.L.; Preiss, H.; Parlitz, B.; Krumeich, F.; Lieske, H. Zirconia/carbon composites as monofunctional catalysts in $\mathrm{C}_{6+}$ alkane aromatization. Appl. Catal. A Gen. 1999, 182, 385-397. [CrossRef]

25. Machado, B.F.; Serp, P. Graphene-based materials for catalysis. Catal. Sci. Technol. 2012, 2, 54-75. [CrossRef]

26. Maldonado-Hódar, F.J. Advances in the development of nanostructured catalysts based on carbon gels. Catal. Today 2013, 218-219, 43-50. [CrossRef]

27. Maldonado-Hódar, F.J. Metal-doped carbon aerogels as catalysts for the aromatization of n-hexane. Appl. Catal. A Gen. 2011, 408, 156-162. [CrossRef]

28. Maldonado-Hódar, F.J. Platinum supported on carbon aerogels as catalysts for the n-hexane aromatization. Catal. Commun. 2012, 17, 89-94. [CrossRef]

29. Maldonado-Hódar, F.J.; Jirglová, H.; Morales-Torres, S.; Pérez-Cadenas, A.F. Influence of surfactants on the physicochemical properties and catalytic behaviour of Mo-doped carbon xerogels. Catal. Today 2018, 301, 217-225. [CrossRef]

30. Tshabalala, T.; Scurrell, M. Aromatization of n-hexane over Ga, Mo and Zn modified H-ZSM-5 zeolite catalysts. Catal. Commun. 2015, 72. [CrossRef]

31. Huyen, P.T.; Trinh, V.D.; Teresa Portilla, M.; Martínez, C. Influence of boron promotion on the physico-chemical properties and catalytic behavior of Zn/ZSM-5 in the aromatization of n-hexane. Catal. Today 2020. [CrossRef]

32. Pérez-Cadenas, A.F.; Maldonado-Hódar, F.J.; Moreno-Castilla, C. Molybdenum Carbide Formation in Molybdenum-Doped Organic and Carbon Aerogels. Langmuir 2005, 21, 10850-10855. [CrossRef]

33. Delporte, P.; Pham-Huu, C.; Ledoux, M.J. Effect of the reaction temperature and hydrocarbon partial pressure on the activity of carbon-modified $\mathrm{MoO}_{3}$ for n-hexane isomerization. Appl. Catal. A Gen. 1997, 149, 151-180. [CrossRef]

34. Ledoux, M.J.; Huu, C.P.; Guille, J.; Dunlop, H. Compared activities of platinum and high specific surface area $\mathrm{Mo}_{2} \mathrm{C}$ and $\mathrm{WC}$ catalysts for reforming reactions: I. Catalyst activation and stabilization: Reaction of n-hexane. J. Catal. 1992, 134, 383-398. [CrossRef]

35. Rahman, M.; Sridhar, A.; Khatib, S.J. Impact of the presence of Mo carbide species prepared ex situ in Mo/HZSM-5 on the catalytic properties in methane aromatization. Appl. Catal. A Gen. 2018, 558, 67-80. [CrossRef]

36. Morales-Torres, S.; Pastrana-Martínez, L.M.; Maldonado-Hódar, F.J. Influence of Electrostatic Interactions During the ResorcinolFormaldehyde Polymerization on the Characteristics of Mo-Doped Carbon Gels. Processes 2020, 8, 746. [CrossRef]

37. Pekala, R.W. U.S. Patent 4997804, 1991.

38. Maldonado-Hódar, F.J.; Ferro-García, M.A.; Rivera-Utrilla, J.; Moreno-Castilla, C. Synthesis and textural characteristics of organic aerogels, transition-metal-containing organic aerogels and their carbonized derivatives. Carbon 1999, 37, 1199-1205. [CrossRef] 